\title{
PETERS, Jan, Gutsherrschaft als soziales Modell. Vergleichende Betrachtungen zur Funktionsweise frühneuzeitlicher Agrargesellschaften
}

\section{Christophe Duhamelle}

\section{(2) OpenEdition}

\section{Journals}

Édition électronique

URL : http://journals.openedition.org/ifha/1531

DOI : 10.4000/ifha.1531

ISSN : 2198-8943

Éditeur

IFRA - Institut franco-allemand (sciences historiques et sociales)

Référence électronique

Christophe Duhamelle, «PETERS, Jan, Gutsherrschaft als soziales Modell. Vergleichende Betrachtungen zur Funktionsweise frühneuzeitlicher Agrargesellschaften », Revue de l'IFHA [En ligne], Date de recension, mis en ligne le 01 janvier 1997, consulté le 22 septembre 2020. URL : http://journals.openedition.org/ ifha/1531 ; DOl : https://doi.org/10.4000/ifha.1531

Ce document a été généré automatiquement le 22 septembre 2020.

(C)IFHA 


\title{
PETERS, Jan, Gutsherrschaft als soziales Modell. Vergleichende Betrachtungen zur Funktionsweise frühneuzeitlicher Agrargesellschaften
}

\author{
Christophe Duhamelle
}

Issu d'un colloque de 1993, ce recueil rassemble les premiers résultats du groupe de travail de la Max-Planck-Gesellschaft sur la Gutsherrschaft. Le groupe, situé à l'Université de Potsdam, est marqué à la fois par l'héritage d'une historiographie estallemande sensible, surtout dans les derniers temps, aux problèmes de l'histoire rurale, et par la volonté de refonder cette recherche sur des options nouvelles, présentes également dans des travaux récents de l'»ouest" et toujours soumises à la controverse; les 62 pages (!) de discussions souvent animées publiées en fin de volume en font foi. Le choix d'un objet assez négligé (la seigneurie orientale, longtemps identifiée au seul "second servage«), mais surtout la définition d'une approche concrète, microhistorique, soucieuse de rétablir la diversité des stratégies paysannes et de privilégier l'étude des archives locales (J. PETERS), confèrent à l'ouvrage une féconde originalité et aux vingt-deux contributions, venues en partie d'horizons plus larges que le centre de Potsdam, une harmonie de thèmes et de méthodes rarement atteinte dans un livre collectif de cette ampleur. On en esquissera quelques thèmes communs, au risque d'être réducteur et surtout de gommer ce qui est à la fois une des richesses et un des présupposés méthodologiques de cet ouvrage: la multiplicité des cas. Cette diversité doit être soulignée d'emblée. Elle contribue d'abord à briser l'image convenue d'une seigneurie "tyrannique« à l'est de l'Elbe et »légère« à l'ouest. La comparaison avec les cas rhénan (H. GABEL), autrichien (H. VALENTINITSCH) ou même bourguignon (W. SCHMALE) permet d'aboutir à des conclusions plus nuancées. Mais c'est aussi dans le domaine oriental lui-même que l'espace est pluriel et que la domination seigneuriale a parfois du mal à s'imposer, sur la côte ouest du Holstein par exemple (K.-J. LORENZENSCHMIDT). La diversité spatiale, les nuances apportées à la vision trop massive de la Gutsherrschaft, ne découlent cependant pas seulement de l'accumulation des études de 
cas, mais aussi de la perspective adoptée par les auteurs. En effet, en privilégiant à la fois les comportements concrets sur les textes normatifs (sinon pour en souligner les faiblesses: M. WEBER) et l'analyse stratégique multifactorielle sur une conception agonistique des agrégats sociaux, nombreuses sont les communications à montrer que même la seigneurie la plus »dure « n'ignore ni les compromis ou les réciprocités entre dominants et dominés (voir l'analyse des prestations de serments menée par A. HOLENSTEIN), ni la vie communale (T. RUDERT sur la Haute-Lusace), ni surtout les formes innombrables de résistances larvées ou ouvertes, mais en tout cas organisées (S. GÖTTSCH). A cet égard, l'usage massif et parfois vainqueur que les paysans font du droit s'impose comme un thème récurrent de l'ouvrage, du recours aux tribunaux d'Empire (W. TROSSBACH montre les appropriations spécifiques de l'espace et de l'écrit qui sous-tendent les actions juridiques des paysans) et aux juridictions territoriales (M. SCHATTKOWSKY) jusqu'aux justices seigneuriales. Celles-ci, loin d'apparaître comme les instruments brutaux de la domination, semblent offrir parfois des garanties aux paysans, ou en tout cas fonctionner en grande partie à leur initiative. C'est en effet la vie propre des communautés villageoises, les conflits qui les traversent et leur attitude envers l'institution seigneuriale qui constitue le troisième thème de l'ouvrage. L'étude des relations entre les femmes et les hommes permet en particulier cette approche de l'usage différencié des basses juridictions: non seulement ces archives permettent de déceler le rôle évolutif des deux sexes au village, mais elles révèlent sur ce point la flexibilité d'un système de domination utilisé aussi par les »dominés« eux-mêmes (U. GLEIXNER; M. HOHKAMP; M. MOMMERTZ). La tentative de typologie des »styles de vie« individuels semble en revanche moins convaincante.

2 A l'est de l'Elbe, les paysans ne sont donc pas tous misérables (W. HAGEN), imperméables au progrès (C. ZIMMERMANN), ni plongés dans une soumission apathique (L. ENDERS). Mais alors pourquoi la Gutsherrschaft s'impose-t-elle à l'est et pas à l'ouest? La question est plusieurs fois posée, comme un appel au retour vers des explications plus globales ou vers d'autres perspectives. On touche là à une des limites du travail entrepris à Potsdam; pour l'instant, elle pèse cependant peu au regard de tout ce que cet ouvrage permet de découvrir de concret, de divers, de complexe, de vie, dans une histoire rurale allemande qui en manque souvent trop. 